\title{
Study on the Infrared Spectra of Superoxide Dismutase with the Different Treatment Intensity of Electric Field
}

\author{
Siqin-gaowa BAO ${ }^{1, a,{ }^{*},}$ Yan-ru WANG ${ }^{1}$, Zhi-chao $\mathrm{CHEN}^{1}$, Zhao WEI ${ }^{1}$, \\ Altantuya $^{2}$ and Zhan-xin $\mathrm{MA}^{2}$ \\ ${ }^{1}$ School of Science, Inner Mongolia University of Technology Hohhot 010051, China \\ ${ }^{2}$ School of Mathematical Science, Inner Mongolia University Hohhot 010021, China \\ abaosiqingaowa@163.com \\ ${ }^{*}$ Corresponding author
}

Keywords: Electric Fields, Superoxide Dismutase, Infrared Spectra.

\begin{abstract}
With the different treatment intensity of electric field, we analyze the influence of electric field on infrared spectra of superoxide dismutase by using infrared spectra method. The results show that, superoxide dismutase (SOD) is treated with different electric field intensity, the absorption peak of the absorption spectrum on one dimensional infrared spectrum is changed. When the electric field intensity is 2.5 $\mathrm{kV} \cdot \mathrm{cm}-1$, it is most obvious, the peak values are greater than the control group. On the other hand, when the electric field intensity is $4.5 \mathrm{kV} \cdot \mathrm{cm}-1$, the peak values are lower than control group. This confirms the results that the biochemical indicators of seedling of plant seeds treated with electric field intensity is $2.5 \mathrm{kV} \cdot \mathrm{cm}-1$ are significantly better than the corresponding control group. Therefore, we can explain the macro electro biology effect by the micro electro biology effect.
\end{abstract}

\section{Introduction}

Enzyme has the most important role in the life process. The theory research has indicated to the molecule structure of enzyme proteins to extremely important to the function of enzyme, even if the disruption is very subtle, but also can greatly affect the enzyme activity, and enzyme protein is not a rigid molecule, its function depends on the structure of this movement[1]. It has been shown that the electric field treatment can change the enzyme activity that the change process of enzyme activity, which is electric field treatment, causes its statistic electricity character and constructs its activity change [2]. Fourier transform infrared spectra is one type of applied test in polypeptide and protein character's structure, and sensitive instrument [3-5]. Superoxide dismutase (SOD) is a kind of protein which is a specific bio catalysis function in natural organisms. So that to determine the effect of the electric field treatment on the enzyme protein molecule structure the comparative analysis will be conducted the effect of the electric field treatment on the enzyme protein molecule structure. And will provide theoretical support for exploring the macro biology effects of plant seeds by treated by electric field. 


\section{Materials and Methods}

\section{Materials}

Superoxide dismutase (SOD) (purchased form Fu Jian hua Can pharmacy Co., Ltd, specific energy $4163.04 \mathrm{u} \cdot \mathrm{mg}-1$, u enzyme energy units).

\section{Experimental Method}

The Sample Product of Electric Field Treatment. Take appropriate sample product into the electric field. The electric field is formed by the plate electrode, which is even high pressure electric field, high pressure electric field intensity $=$ electric pressure/pole distance. There are eleven of kinds electric field intensities. For examples 0.5, 1.0, 1.5, $2.0,2.5,3.0,3.5,4.0,4.5,5.0$, and $5.5 \mathrm{kV} \cdot \mathrm{cm}^{-1}$ etc. The control group is denoted by $\mathrm{E}_{0}=0.0 \mathrm{kV} \cdot \mathrm{cm}^{-1}$. Electric field treatment time is $10 \mathrm{~min}$.

Fourier Transform Infrared Spectra Test. After SOD is treated with different intensity, SOD and $\mathrm{KBr}$ with1:100 is determined for even mixing pressure piece. Infrared spectra is Nex us 670 Fourier transform infrared spectra (Product of Nicolet company of USA). Spectral range is $400-4000 \mathrm{~cm}-1$ and resolution is $4 \mathrm{~cm}-1$, the infrared spectra were obtained by 32 scans.

Spectra Processing. Using the Microsoft origin 8.0 program to calculate the original spectra and to choose the peak value. Then analyze the peak value and position changes of each absorption peak. According to the influence of electric field intensity on the protein, analyze the post electric field treatment growth of plant seeds.

\section{Experimental Results and Analysis}

Influence of electric field on superoxide dismutase absorption peak.

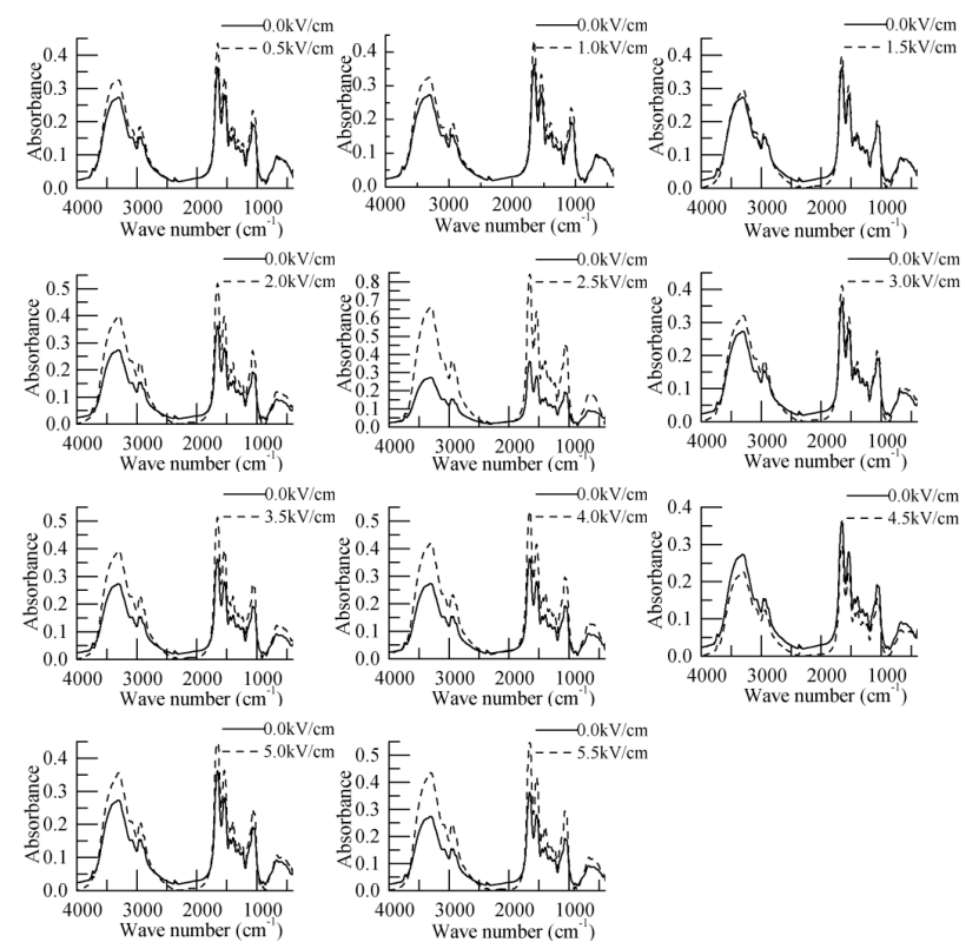

Fig1 The one - dimensional infrared absorption spectra of the superoxide dismutase treated by different electric fields 
The absorption peak of infrared spectra is divided into two regions: $4000 \mathrm{~cm}^{-1} \sim 1130$ $\mathrm{cm}^{-1}$ region: characteristic spectral band, which is the main basis of infrared spectra analysis. $1130 \mathrm{~cm}^{-1} \sim 650 \mathrm{~cm}^{-1}$ region: finger print region. Each compound in the fingerprint has its own characteristic spectrum; determination of the molecular structure can provide important information [6].

Fig 1 shown the one - dimensional spectra of the superoxide dismutase treated by different electric fields. According to the infrared absorption spectra can be obtained, absorption peak of $\mathrm{n}(\mathrm{C}=\mathrm{C})$ stretching vibration $\mathrm{C}=\mathrm{C}$ of alkene is $1640 \mathrm{~cm}^{-1} \sim 1680 \mathrm{~cm}^{-1}$, peak value is $1658 \mathrm{~cm}^{-1}$ point, absorbance is 0.32269 ; absorption peak of $\mathrm{C}-\mathrm{H}$ stretching vibration is high frequency of spectra. $\mathrm{n}\left(\mathrm{Csp}_{3}-\mathrm{H}\right)$ alkane is between 2800 $\mathrm{cm}^{-1}$ and $3000 \mathrm{~cm}^{-1}$, peak value has $2939 \mathrm{~cm}^{-1}$ and $2969 \mathrm{~cm}^{-1}$, absorbance is 0.15380 and 0.15399; $\mathrm{n}\left(\mathrm{Csp}_{2}-\mathrm{H}\right)$ alkene is $3000 \mathrm{~cm}^{-1} \sim 3100 \mathrm{~cm}^{-1}$, peak value is $3093 \mathrm{~cm}^{-1}$, absorbance is 0.15275 . The absorption peak of every production of the bending vibration in all kinds of $\mathrm{C}-\mathrm{H}$ linkage is low frequency region of spectra, $\delta(\mathrm{C}-\mathrm{H})$ of $\mathrm{CH}_{3}$ alkane is around $1450 \mathrm{~cm}^{-1}$ and $1380 \mathrm{~cm}^{-1}$, absorbance is between 0.15365 and 0.15923 . $(\mathrm{C}=\mathrm{C})$ stretching vibration of $\mathrm{C}-\mathrm{C}$ linkage is $1500 \mathrm{~cm}^{-1} \sim 1600 \mathrm{~cm}^{-1}$, peak value is 1546 $\mathrm{cm}^{-1}$ point, absorbance is 0.28027 .

According tofig1 and table1, it can be shown that the 7 absorption peaks of treatment groups $\left(0.5 \mathrm{kV} \cdot \mathrm{cm}^{-1}, 1.0 \mathrm{kV} \cdot \mathrm{cm}^{-1}, 1.5 \mathrm{kV} \cdot \mathrm{cm}^{-1}, 2.0 \mathrm{kV} \cdot \mathrm{cm}^{-1}, 2.5 \mathrm{kV} \cdot \mathrm{cm}^{-1}, 3.0 \mathrm{kV} \cdot \mathrm{cm}^{-1}\right.$, $3.5 \mathrm{kV} \cdot \mathrm{cm}^{-1}, 4.0 \mathrm{kV} \cdot \mathrm{cm}^{-1}, 4.5 \mathrm{kV} \cdot \mathrm{cm}^{-1}$, and $5.0 \mathrm{kV} \cdot \mathrm{cm}^{-1}$ ) are greater than $7 \mathrm{control}$ group's peak. 7 absorption peaks of $4.5 \mathrm{kV} \cdot \mathrm{cm}^{-1}$ treatment group are lower than 7 absorption peaks of control group. There are two causes of the main factors affecting the intensity of infrared spectra: First, the vibration magnitude of dipole moment change. The dipole moment change is more big, the spectrum band intensity also more big, so and dipole moment change relates to radical's dipole, chemical polarity has strong radicals, vibration of dipole moment change is more big, the corresponding absorption spectrum band is strong. Second, energy level transition probabilit. Transition probability is higher; absorption peak also is strong [7]. Therefore, absorption peak enhancement of superoxide dismutase by treated different electric field is the reason for dipole moment and vibration form change. And the magnitude of absorption peak enhancement is also different, which is the most obvious at 2.5 $\mathrm{kV} \cdot \mathrm{cm}^{-1}$. It can be shown that chemical linkage of pair peak is more sensitive to electric field intensity affecting. This is also identical to growth of plant, that is sowing plant seed, which is treated by electro field is greater than every plat's growth in control group. This is also for us to find out the macro effect and the micro effects have a certain path of inherent relationship. When electric field intensity is $4.5 \mathrm{kV} \cdot \mathrm{cm}^{-1}$, the absorption peak is lower than control group. It can be explained that chemical linkage of pair peak is not sensitive to electric field intensity affecting. It means that electric field intensity affecting for enzyme or plant seed is nonlinear, and need to be study its regulations. 
Table 1 The infrared spectra absorption peak of the superoxide dismutase treated by different electric fields

\begin{tabular}{|c|c|c|c|c|c|c|c|}
\hline Absorbance & $\begin{array}{c}\text { The } \mathrm{n} \\
(\mathrm{C}=\mathrm{C}) \\
\text { peak of } \\
\text { the } \\
\text { alkene } \\
\text { is about } \\
1658 \\
\mathrm{~cm}^{-1}\end{array}$ & $\begin{array}{c}\text { The peak } \\
\text { value of } \\
n \\
\text { (Csp3-H) } \\
\text { in alkane } \\
\text { is about } \\
2939 \mathrm{~cm}^{-1}\end{array}$ & $\begin{array}{c}\text { The peak } \\
\text { value of } \\
n \\
(\mathrm{Csp} 3-\mathrm{H}) \\
\text { in alkane } \\
\text { is about } \\
2969 \mathrm{~cm}^{-1}\end{array}$ & $\begin{array}{c}\text { The } \mathrm{n} \\
\text { (Csp2-H) } \\
\text { peak of } \\
\text { the } \\
\text { alkene is } \\
\text { about } \\
3093 \\
\mathrm{~cm}^{-1}\end{array}$ & $\begin{array}{c}\text { The } \delta(\mathrm{C}-\mathrm{H}) \\
\text { peak of } \\
-\mathrm{CH} 3 \text { in } \\
\text { the alkane } \\
\text { is } 1450 \\
\mathrm{~cm}^{-1}\end{array}$ & $\begin{array}{c}\text { The } \delta(\mathrm{C}-\mathrm{H}) \\
\text { peak of } \\
-\mathrm{CH} 3 \text { in } \\
\text { the alkane } \\
\text { is } 1380 \\
\mathrm{~cm}^{-1}\end{array}$ & $\begin{array}{c}\text { The peak } \\
\text { value of } \\
\mathrm{n}(\mathrm{C}=\mathrm{C}) \\
\text { is about } \\
1546 \mathrm{~cm}^{-1}\end{array}$ \\
\hline $0.0 \mathrm{kV} / \mathrm{cm}$ & 0.36269 & 0.15380 & 0.15399 & 0.15275 & 0.15365 & 0.15923 & 0.28027 \\
\hline $0.5 \mathrm{kV} / \mathrm{cm}$ & 0.43529 & 0.18814 & 0.18248 & 0.17664 & 0.18581 & 0.19098 & 0.33363 \\
\hline $1.0 \mathrm{kV} / \mathrm{cm}$ & 0.5214 & 0.22208 & 0.21963 & 0.2134 & 0.213 & 0.22591 & 0.39453 \\
\hline $1.5 \mathrm{kV} / \mathrm{cm}$ & 0.39939 & 0.16116 & 0.16292 & 0.16835 & 0.15665 & 0.17211 & 0.30768 \\
\hline $2.0 \mathrm{kV} / \mathrm{cm}$ & 0.51885 & 0.22347 & 0.22407 & 0.23416 & 0.2053 & 0.22664 & 0.39811 \\
\hline $2.5 \mathrm{kV} / \mathrm{cm}$ & 0.84384 & 0.35998 & 0.35782 & 0.35736 & 0.33718 & 0.36349 & 0.63623 \\
\hline $3.0 \mathrm{kV} / \mathrm{cm}$ & 0.41166 & 0.17975 & 0.18107 & 0.19082 & 0.16482 & 0.18186 & 0.31894 \\
\hline $3.5 \mathrm{kV} / \mathrm{cm}$ & 0.51313 & 0.22418 & 0.22316 & 0.22751 & 0.20733 & 0.22762 & 0.39668 \\
\hline $4.0 \mathrm{kV} / \mathrm{cm}$ & 0.53776 & 0.2323 & 0.2336 & 0.23526 & 0.22594 & 0.23972 & 0.41554 \\
\hline $4.5 \mathrm{kV} / \mathrm{cm}$ & 0.29708 & 0.1243 & 0.12394 & 0.1279 & 0.11602 & 0.12741 & 0.22824 \\
\hline $5.0 \mathrm{kV} / \mathrm{cm}$ & 0.46883 & 0.20404 & 0.20314 & 0.20928 & 0.18907 & 0.20922 & 0.3633 \\
\hline $5.5 \mathrm{kV} / \mathrm{cm}$ & 0.54826 & 0.23836 & 0.24057 & 0.24438 & 0.21726 & 0.23685 & 0.41915 \\
\hline
\end{tabular}

\section{Acknowledgement}

Natural Science Foundation of Inner Mongolia (2014MS0351), "College student innovative experiment program" Foundation of Inner Mongolia University of Technology 2015 annual (2015046)

\section{Conclusions}

The above analysis is shown that the distribution and movement of a variety of charged matter in organisms have more importance to the living process. When the external environmental changes, it will inevitably lead to changes in the organism of the biological situation, so as to achieve new biological situation, and affecting the living process. The external electric field affects to vibration of chemical linkage in the protein, and the absorption peak value is also affected. There are two causes of the main factors affecting intensity of infrared spectra: 1 . vibration magnitude of dipole moment change. 2. Energy level transition probabilit. And magnitudes of dipole moment change relate to the following: (1) Electronegativity of atoms; (2) Vibration mode; (3) Molecular symmetry; (4) Couple interaction etc. Therefore, absorption peak enhancement of super oxide dismutase by treated different electric field is the reason for dipole moment and vibration form change. And the magnitude of absorption peak enhancement is also 
different, which is the most obvious at $2.5 \mathrm{kV} \cdot \mathrm{cm}^{-1}$. It can be shown that chemical linkage of pair peak is more sensitive to electric field intensity affecting. This is also identical with growth of plant, that is sowing plant seed, which is treated by electro field is greater than every plat's growth in control group. This is also for us to find out the macro effect and the micro effects have a certain path of inherent relationship.

\section{References}

[1] Bo-lin HAO, Ji-xing LIU, Theoretical Physics and Life Science, Shanghai Scientific and Technological Education Press, Shanghai, 1997(in Chinese).

[2] Xin-an ZENG, Da-wei GAO, Guo-ji LI, et al, Food Science. 18 (1997) 3(in Chinese).

[3] Wei LU, Chun-he XU, Rong LI, et al, Spectroscopy and Spectral Analysis. 22 (2002) 749 (in Chinese).

[4] Hua DENG, Zhan-jun SONG, De-wen WANG, et al, Spectroscopy and Spectral Analysis. 26(2006) 1437 (in Chinese).

[5] Dong A, Huang P, Caughey W S, Arch. Biochem. Biophys. 320 (1995) 59.

[6] Xun Ying JIN, Shi Lu CHEN, En Hong YAO, Practical guide for infrared spectroscopy, Tianjin science and Technology Press, Tianjin, 1992(in Chinese).

[7] Xiao Kun ZHAO, Factors affecting infrared absorption spectrum intensity, Inner Mongolia Petrochemical Industry. 12(2007)179-181. 